\title{
2009年米領サモア地震津波における津波被害関数の構築
}

\section{Developing Tsunami Fragility Curves Due to the 2009 Tsunami Disaster in American Samoa}

\author{
郷右近英臣 $^{1} \cdot$ 越村俊 ${ }^{2} \cdot$ 松岡昌志 $^{3} \cdot$ 行谷佑 $^{4}$ \\ Hideomi GOKON, Shunichi KOSHIMURA, Masashi MATSUOKA and Yuichi NAMEGAYA
}

The authors developed the tsunami fragility curves due to 2009 samoa earthquake tsunami, to investigate structural vulnerability in the affected area, by integrating satellite remote sensing, field survey, numerical modeling, and GIS analysis. In this paper, the authors propose three kind of tsunami fragility curves of structural destruction with regard to the inundation depth, current velocity, and hydrodynamic force.

\section{1. 序論}

\section{(1) 研究の背景・目的}

2009年9月 29 日, 米領サモア南西 $180 \mathrm{~km}$ を震源とする Mw8.1の地震が発生した. 地震に伴い発生した津波は, サモア諸島・トンガを襲い，死者・行方不明者は約 200 人に達した。発災後, 複数の機関による現地調査が行わ れ，浸水深・遡上高のような津波流況や，人的・物的被 害のような実被害の実態が明らかにされてきた（行谷ら， 2010).しかし，これらの成果を，サモアおよび米国の 津波対策に活かすためには，被害実態を津波被害評価式 という形に置き換える必要がある。本研究では, 現地調 査および衛星画像からの家屋被害の判読結果と津波数值 解析とを統合し, 津波被害関数を構築することを目的と する。

津波被害関数とは, 津波数值解析技術の高度化および リモートセンシング技術・地理情報システム（GIS）の 普及を背景に提案された，新しい津波被害想定指標であ り，津波による建物・人的被害の程度を被害率 (死亡率) という尺度で, 津波の流体力学的諸量（浸水深, 流速, 波力等）の関数として表すものである（越村ら，2009）.

\section{(2) 本研究の流れ}

まず，非線形長波式に基づく津波数值解析を行い，現 地調査結果との検証を踏まえて, 米領サモア (Tutuila島) に来襲した津波の流況を再現する。次に，被災前後の高 解像度衛星画像を GIS 上で同一座標系に統合し，津波被 災地の建物被害を一件一件目視判読する。判読結果は, 現地調査結果に基づく家屋の悉皆調査により，精度向上 を図る。最後に，津波汇監解析結果と建物被害判読結果

$\begin{array}{lll}1 & \text { 学生会員 } & \\ 2 & \text { 正会員 } & \text { 博 (工) } \\ 3 & & \text { 博 (工) } \\ 4 & \text { 正会員 } & \text { 博 (工) }\end{array}$

東北大学大学院工学研究科

東北大学准教授 大学院工学研究科 産業技術総合研究所 地質調査情報センター 産業技術総合研究所研究員 活断層・地震 研究センター
をGIS 上で統合分析することにより，津波被害関数の構 築を行う.

\section{2. 現地調査}

本研究の対象領域は，被災前後の高解像度衛星画像の セットが手に入り，さらに現地調査により詳細な被害状 況, 地形の情報が得られた米領サモアのPago Pago, Leone，Poloa，Amanaveとする（図-1)。現地調查は被災 直後と, 被災から 10 ケ月後の 2 回行われた。被災直後の 調査は被害の実態解明を目的とし，著者らにより，浸水 域や, 浸水深等の津波流況, 家屋被害の悉皆調査が行わ れた。被災から10 ケ月後の調查では，津波氾濫解析に使 用する地形モデルを補正するため，キネマティック GPS による高精度地形測量を行った。

\section{3. 津波数値解析}

\section{(1) 地形データの作成}

地形データは，30秒メッシュの General Bathymetric Chart of the Oceans (GEBCO) を，27秒から1秒へと格

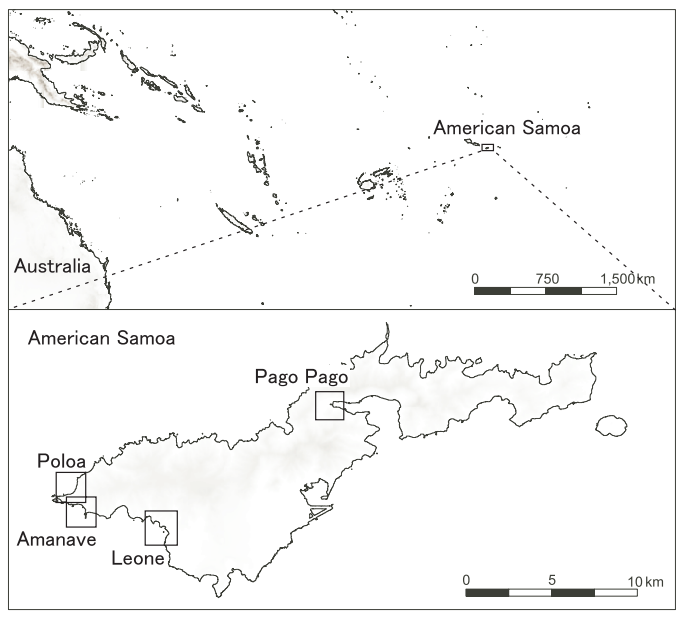

図-1 本研究の対象領域 


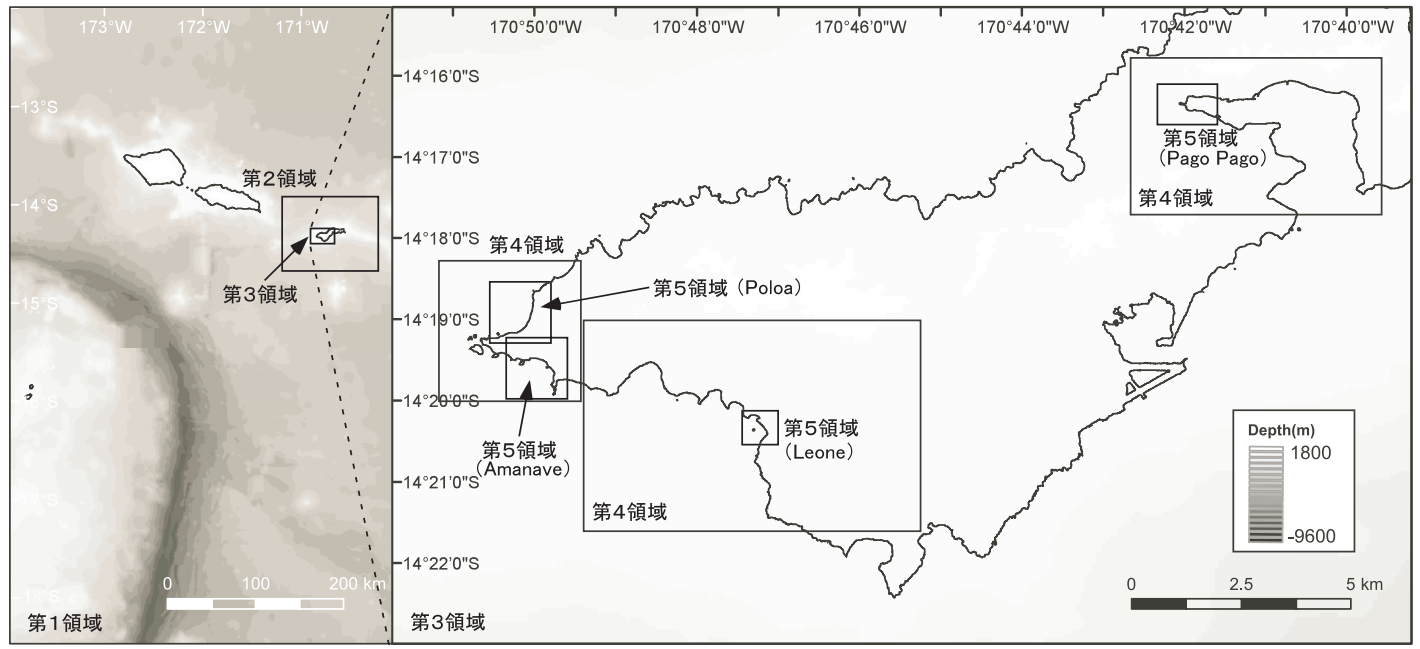

図-2 津波数值解析に使用する領域

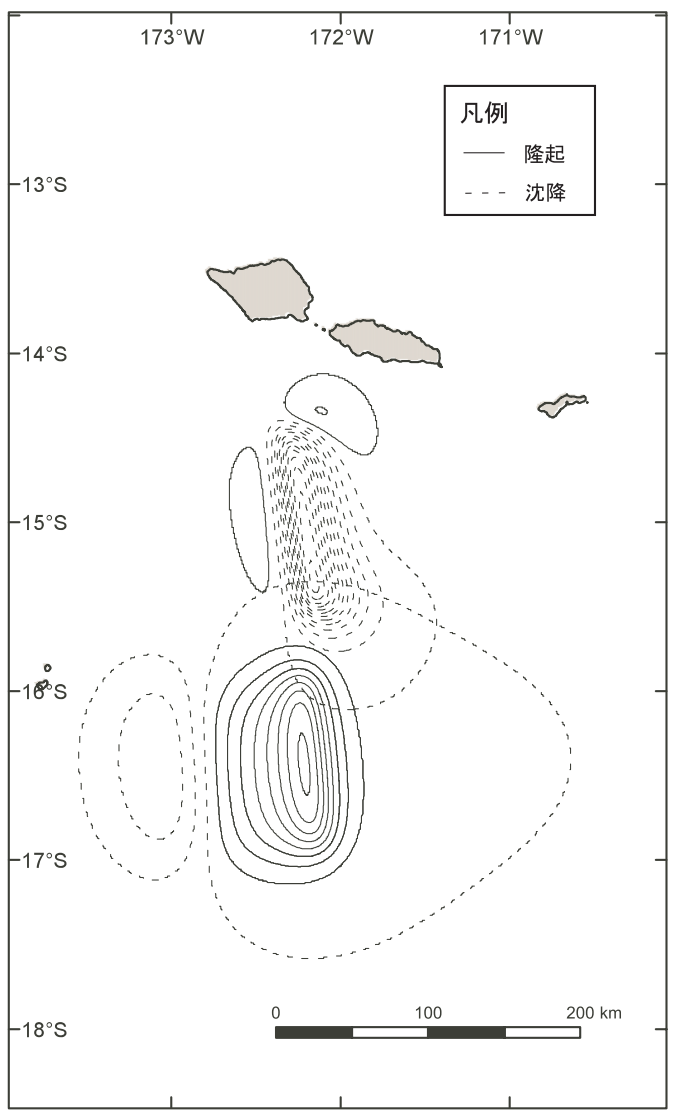

図-3 初期水位分布（Beavan ら，2010）

子間隔が3分の 1 ずつになるようにネスティングしたも

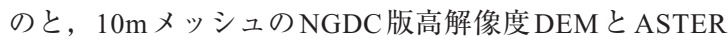
GDEMを組み合わせたものを，大領域から小領域へ接続 することにより作成した（図-2)．浸水域に抒ける地形の 再現性を高めるために, キネマティック GPSによる高精
表-1 Beavanら（2010）の提案した断層パラメータ

\begin{tabular}{l|c|c}
\hline 断層パラメータ & 正断層 & 逆断層 \\
\hline 断層位置 (緯度) & -15.542 & -15.940 \\
断層位置 (経度) & -172.237 & -172.718 \\
走向 ${ }^{\circ}$ ) & 352 & 175 \\
傾斜角 ( $\left.{ }^{\circ}\right)$ & 48 & 16 \\
滑り角 $\left({ }^{\circ}\right)$ & -41 & 85 \\
断層長さ $(\mathrm{km})$ & 114 & 109 \\
断層幅 $(\mathrm{km})$ & 28 & 90 \\
断層深さ $(\mathrm{km})$ & 13 & 18 \\
滑り量 $(\mathrm{m})$ & 8.6 & 4.1 \\
\hline
\end{tabular}

度地形測量を行い，GIS 上でDEMの補正を行った。底面 摩擦はマニング式により算出し, 特に人口密度の高い領 域では, 家屋占有率に基づく抵抗則を適用した （Koshimura ら，2009）。家屋の位置は, 津波被災前の被 災地を捉えたQuickBird衛星画像（2009年9月24日撮影） およびIKONOS衛星画像（2007年4月15日撮影）より家 屋ポリゴンを作成することで特定した.

\section{(2) 津波氾濫解析}

以上の地形デー夕を使用して, 非線形長波式に基づく 津波遡上計算を, 米領サモアのPago Pago, Leone, Poloa, Amanaveの4領域において実施した。波源は，これまで に提案されたBeavanら（2010）とLayら（2010）の二つ のモデルのうち，詳細な記述のある Beavanら（2010）の 断層パラメー夕（表-1）を参考にし, 津波数值解析結果 が 4 領域の浸水深や浸水域をそれぞれ十分再現するよう に，断層滑り量を調整した（図-3).Pago Pagoでは，痕 跡高を数十点計測したので，Aida（1978）の判定式を用 いて, 解析結果の検討を行った. 本判定式は, 幾何平均 $K$ および，幾何標準偏差 $\kappa$ に基づき，現地調查結果等の ような測定值を使用することで, 津波数值解析結果の再 現性の検証の際に使用されるものである. 特に Pago Pago では, $K=0.97, \kappa=1.13$ を得ており, 土木学会が提案 

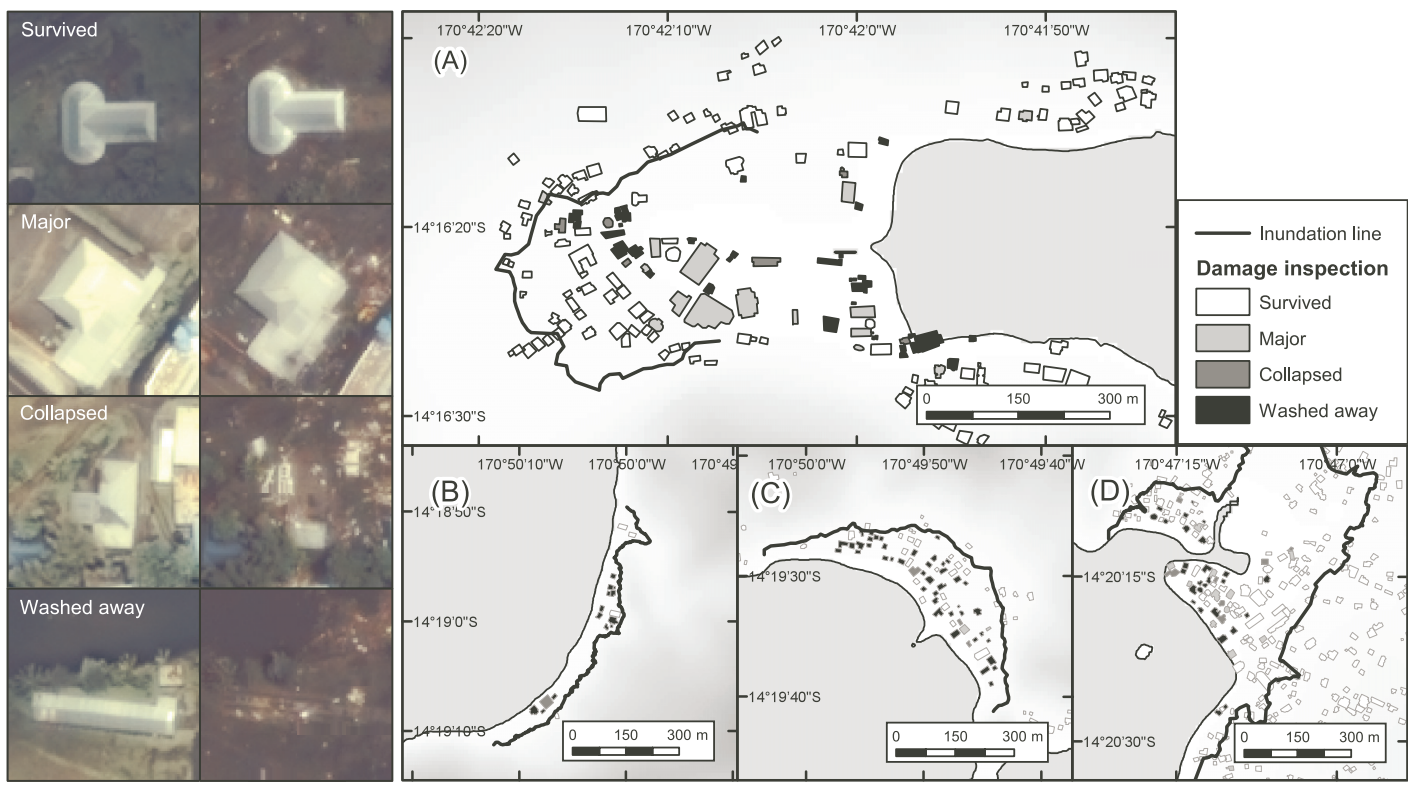

図-4 左図；建物被害判読基準（左：被災前，右：被災後)，右図；被害判読結果（(A) PagoPago，（B） Poloa，（C）Amanave，（D） Leone)

している, 痕跡高を用いた津波計算の妥当性の基準 $(0.95<K<1.05, \quad \kappa<1.45)$ を満たしている. また，その他 の 3 領域では, 浸水深の計測地点数が津波数值解析結果 を検討する上で不十分であると判断し, 主に, 瓦砂漂着 ラインを検討に使用した.

\section{4. リモートセンシングによる家屋被害判読}

津波被災地を捉えた被災前後の高解像度衛星画像を GIS 上で同一座標系上に表示し，建物屋根の形状変化に 着目した家屋被害調查を行った。被災前の衛星画像には, 米国GeoEye 社のIKONOS衛星画像（2007年4月15日） および, 米Digital Globe社のQuickBird衛星画像（2009年 9月24日）を使用し, 被災後の衛星画像として米Digital Globe社のQuickBird衛星画像（2009年9月29日，2009年 10 月 2 日，2009年 11 月 2 日撮影）を使用した.

本研究では, PagoPago, Leone, Poloa, Amanaveの 4 領域において, 現地調査により判明した浸水域内家屋 451 棟を対象とし, 衛星画像を用いて家屋被害の目視判 読を実施した。被害の程度は, Miuraら（2006）が提案 した基準を参考にし, Survived, Major damage, Collapsed, Washed-awayの4段階に分類した（図-4:左図）。さらに， 現地調査による家屋被害悉皆調査結果を併用することに より，建物被害分類の精度向上を図った。以上の過程に より得られた，家屋被害の調查結果を図-4:右図と表-2に 示す.
表-2 建物被害判読結果

\begin{tabular}{l|c}
\hline Damage category & 家屋数 [PagoPago/Amanave/Poloa/Leone/計] \\
\hline a) Washed-away & $34 / 42 / 13 / 28 / 117$ \\
b) Collapsed & $7 / 3 / 1 / 7 / 18$ \\
c) Major damage & $14 / 2 / 0 / 12 / 28$ \\
d) Survived & $54 / 34 / 4 / 196 / 288$ \\
\hline
\end{tabular}

\section{5. 津波被害関数の構築}

\section{（1）被害関数とは}

津波被害関数とは, 家屋・人的被害の規模を津波氾濫 流の流体力学的な諸量との関連で記述したものである (Koshimura ら, 2009)。一般的には，津波被害関数は，被 害情報（家屋被害率 $P_{D}$ ） と津波流況の関連性を回㷌分析 により求め, 対数正規分布や正規分布を仮定した次式で 表される。

$$
\begin{aligned}
& P_{D}(x)=\Phi\left[\frac{\ln x-\lambda}{\xi}\right] \\
& P_{D}(x)=\Phi\left[\frac{x-\mu}{\sigma}\right] \cdots
\end{aligned}
$$

ここで, $x$ は最大流速, 最大浸水深, 津波外力などの外

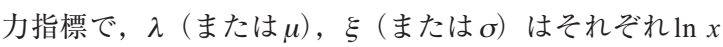
または $x$ の平均值と標準偏差である.

\section{(2) 津波被害関数の構築}

数值解析により求めた津波流況と, 家屋被害の悉皆調 査結果を GIS 上で統合分析し, 最大流速, 最大浸水深, 最大抗力の3つの外力指標と, 家屋被害率に関する津波 被害関数を構築する。津波被害関数の構築は, 越村ら （2009）の手法を踏襲し，Major damage以上の被害を受 


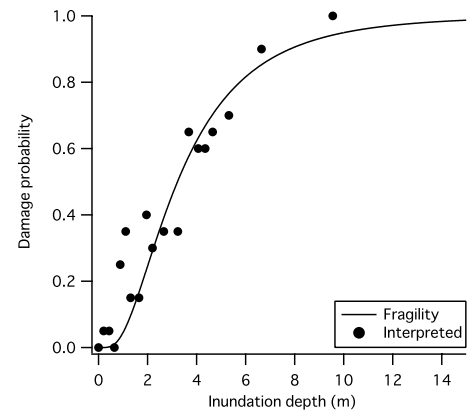

図-5 津波被害関数（浸水深）

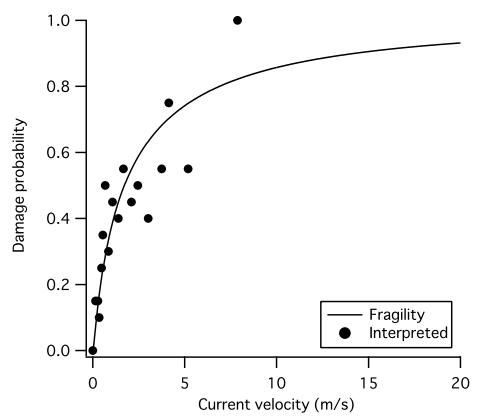

図-6 津波被害関数（最大流速）

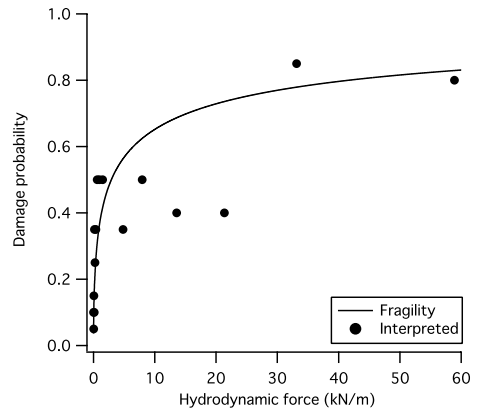

図-7 津波被害関数（最大抗力）
表-3 津波被害関数の回帰式のパラメー夕（N/Aではパラメー 夕同定を行っていない.). $R^{z}$ は回帰式の決定係数.

\begin{tabular}{c|ccccc}
\hline 外力 & $\mu$ & $\sigma$ & $\lambda$ & $\varepsilon$ & $R^{2}$ \\
\hline 浸水深 $(\mathrm{m})$ & N/A & N/A & 1.17 & 0.69 & 0.89 \\
流速 $(\mathrm{m} / \mathrm{s})$ & N/A & N/A & 0.54 & 1.65 & 0.73 \\
抗力 $(\mathrm{kN} / \mathrm{m})$ & N/A & N/A & 1.07 & 3.16 & 0.72 \\
\hline
\end{tabular}

けた家屋を「被害あり」，それ以外の家屋は「被害なし」 と判定した。

本研究で構築した津波被害関数を図-5, 図-6, 図-7に, 津波被害関数の回帰式に使用したパラメー夕を表-3に示す.

\section{（3）津波被害関数の検証}

図-5より，米領サモアの建物は浸水深が $6 \mathrm{~m}$ を超える とほほ $80 \%$ が甚大な被害を受けていたことがわかった. また，浸水深が $2 \mathrm{~m}$ 程度の領域に打いても20～30\%の家 屋が被害を受けていた。

氾濫流速については，およそ最大流速が $5 \mathrm{~m} / \mathrm{s}$ 超える と, 浸水域内の $80 \%$ 以上の建物が壊滅的な被害を受ける 事がわかった（図-6）。特に，流速が $1 \mathrm{~m} / \mathrm{s}$ 程度の場所で も，半分程度の建物が被害を受けている。現時点では津 波数值解析における汇濫流速の推定精度を検証すること はできないが，流速が低くても水位の上昇による浮力で 家屋被害が搪大した可能性がある。

最大抗力については， $10 \mathrm{kN} / \mathrm{m}$ 以下の地域において被害 率が急上昇し，10〜20kN/mに打ける被害率のばらつき が大きくなる (図-7). 従って, 現時点では被害関数とし ての利用は避けるべきである，氾濫流速の再現精度をあ わせてょり詳細な解析が必要である.

米領サモアに打ける調査地域内の建物は，主に一般家 庭の木造家屋, 教会や大規模商業施設のような $\mathrm{RC}$ 構造 物，柱と屋根で作られた簡易的な円形の集会場（屋根部 分は木造）に分類できる. 衛星画像の解析と, 現地調查 の結果，一般家庭の木造建物は津波により壊滅的な被害 を受けたが，それ以外の鉄筋やコンクリート製の構造物， 円形の集会場は, 構造的には比較的軽微な被害で済んだ. 流速が低くても，浸水深が大きくなると，木造建物は浮 力により浮いた後，流失してしまう可能性が高い。鉄筋
コンクリート製の構造物は，今回の津波では流失した例 は無かった。柱と屋根のみの構造物は, 津波を受け流す 作りとなっているため, 船舶のような大規模漂流物が衝 突しない限りは，残存する可能性が高い.

\section{（4）津波危険地域の提示}

ここでは, 本研究の対象領域のうち, 米領サモアの中 心都市であるPagoPagoに押いて, 津波数值解析結果と被 害関数に基づき，建物被害のリスクが大きくなる地域を 示す. 浸水深, 最大流速, 最大抗力と被害率の関係を示 す3種の津波被害関数のうち, 最も回帰式の決定係数が 高い浸水深の津波被害関数を使用する. 図-5より, 浸水 深が $4 \mathrm{~m}$ を超えると, 被害率が拈よそ $60 \%$ に達すること がわかる.これを一つの基準とし, 津波氾濫解析結果に おいて浸水深が $4 \mathrm{~m}$ 以下となる領域を，図-8に示す。

図中に扔いて，推定被害率 $60 \%$ 以上の領域内の建物 28 件のうち，構造的被害を受けた建物は20件，軽微な被害 を受けた建物は 8 件あり，被害率は $71.5 \%$ である。推定 被害率 $60 \%$ よりも若干過大とはいえ，危険領域を示すと いう実用性の観点からは，十分な精度であると考えられ る．津波の汇濫解析を島全体で行うことにより，図-8に 示したように，具体的に津波による被害リスクと地理情 報を関連づける事ができ，これらは今後，米国拉よびサ モア諸島の防災計画策定に, 大きく寄与することが期待 される.

\section{6. 結論}

本研究では，2009年サモア地震津波被災地の米領サモ ア（Tutuila島）において，リモートセンシングと津波数 值解析を GIS 上で統合することにより，新しい津波被害 評価式である津波被害関数を構築した。本関数は, 津波 外力指標（浸水深, 最大流速, 最大抗力） と, 建物被害 率を関連づけたものである。米領サモアの中心都市Pago Pagoに損いて具体的に被害率 $60 \%$ 以上と判定された領域 を示すことにより，本関数の精度検証を行うとともに， その有効性を実証した。

また，本研究で構築した津波被害関数により，米領サ 


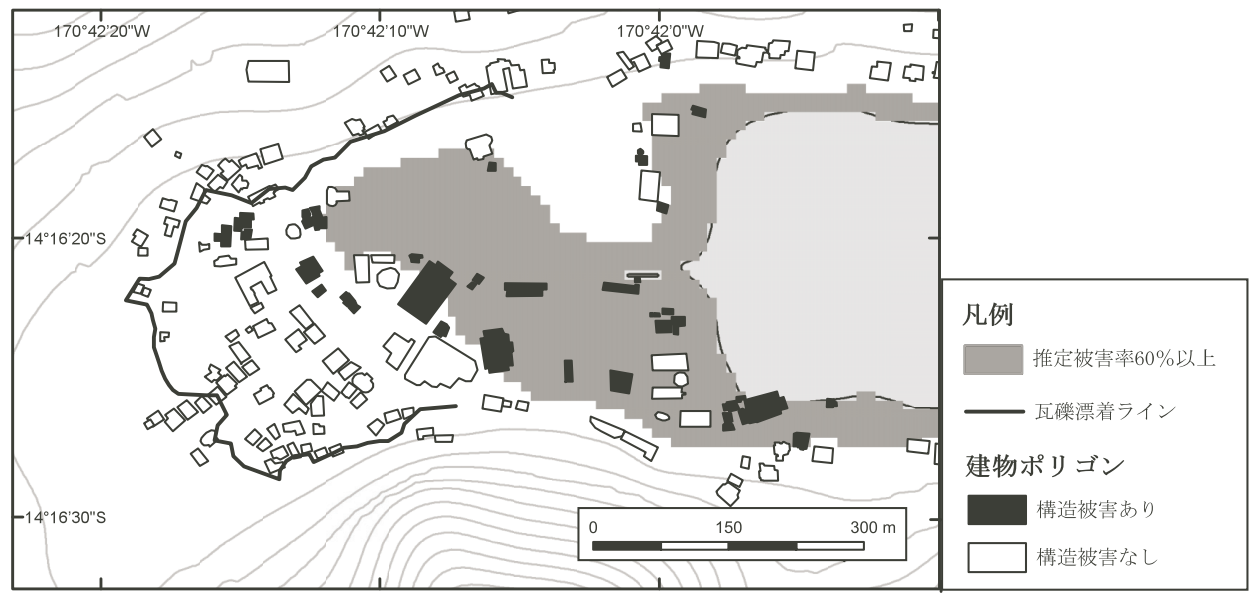

図-8 津波被害関数に基づいて推定した建物被害率 60\%のゾーニング

モアとその周辺の地域において, 浸水深 $6 \mathrm{~m}$ 以上の津波 が到達する領域では，80\%以上の家屋が構造的破壊を受 けることを明らかにした。

謝辞 : 本研究の一部は平成 20 年度産業技術研究助成事業 （プロジェクトID：08E52010a）および科学研究費補助 金（課題番号：22681025）の補助を受けて実施された. ここに記して謝意を表する。

\section{参 考 文 献}

越村俊一・行谷佑一・柳澤英明（2009）: 津波被害関数の構築, 土木学会論文集 B, Vol.65, No.4, pp.320-331.

行谷佑一, 越村俊一, 西村裕一, 中村有吾, Fryer Gerard, Akapo Akapo, Kong S. L. Laura; “2009年サモア諸島沖地震津波の 米領サモアにおける津波高さおよび被害の調査”，土木学 会論文集 B2 (海岸工学), Vol. 66, No. 1, pp.1366-1370 2010.

Aida, I.: Reliability of a tsunami source model derived from fault parameters, J. Phys. Earth, Vol.26, pp.73-75,1978

Beavan, J., X. Wang, C. Holden, K. Wilson, W. Power, G. Prasetya,
M. Bevis and R. Kautoke (2010): Near-simultaneous great earthquakes at Tongan megathrust and outer rise in September 2009, Nature, Vol 466, 19, doi:10.1038/nature09292

IOC, IHO and BODC (2003): Centenary Edition of the GEBCO Digital Atlas, published on CD-ROM on behalf of the Intergovernmental Oceanographic Commission and the International Hydrographic Organization as part of the General Bathymetric Chart of the Oceans, British Oceanographic Data Centre, Liverpool, U.K.

Koshimura, S., Y. Nishimura, Y. Nakamura, Y. Namegaya, G. J. Fryer, A. Akapo, L. Kong and D. Vargo (2009): Field survey of the 2009 tsunami in American Samoa, Eos Trans. AGU, 90(52), Fall Meet. Suppl., Abstract U23F-07.

Lay, T., C. J. Ammon, H. Kanamori, L. Rivera, K. D. Koper, A. R. Hutko (2010): The 2009 Samoa?Tonga great earthquake triggered doublet, Nature, Vol. 466, 19, doi:10.1038/ nature09214.

Miura, H., A. Wijeyewickrema, and S. Inoue (2006): Evaluation of tsunami damage in the eastern part of Sri Lanka due to the 2004 Sumatra earthquake using remote sensing technique, Proc. 8th National Conference on Earthquake Engineering, Paper No.8, NCEE-856. 